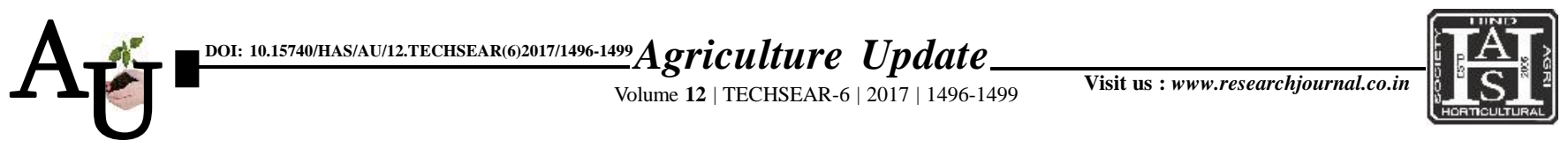

\title{
Research Aвticle: Identification of best restorers and maintainers in rice genotypes through test cross nursery
}

\section{SRIKANTH THIPPANI, S. SUDHEER KUMAR, P. SENGUTTUVEL AND S. NARENDER REDDY}

Article Chronicle : Received : 17.07.2017;

Accepted :

01.08 .2017

KEY Words :

Hybrid rice, Restorers,

Maintainers, Pollen sterility,

Spikelet fertility

Author for correspondence :

\section{SRIKANTH THIPPANI}

Department of Genetics and Plant Breeding, College of agriculture, Professor Jayashankar Telangana State Agricultural University, HYDERABAD (TELANGANA) INDIA

See end of the article for authors' affiliations
SUMMARY : Hybrid rice systems are based on three line cytoplasmic male sterility (CMS) which has been an efficient tool in commercialization of hybrid rice technology. Therefore, identification of potential restorers in rice is the basic step in development of rice hybrids. In present study, 39 lines were crossed to one cytoplasmic male sterile line i.e. IR-79156A, $\mathrm{F}_{1} \mathrm{~s}$ were analyzed for pollen fertility (1\% I-KI solution) and spikelet fertility. Based on the fertility restoration in $\mathrm{F}_{1} \mathrm{~s}, 32$ genotypes were restorers and 7 partial restorers were obtained. Among the 39 lines, AR-7-75, TCP-650, AR-19-18, TCP-657, AR-19-42, TCP-661, AR-9-21, TCP-585, AR-7-65 and TCP-643are considered as promising restorers.

How to cite this article : Thippani, Srikanth, Kumar, S. Sudheer, Senguttuvel, P. and Reddy, S. Narender (2017). Identification of best restorers and maintainers in rice genotypes through test cross nursery. Agric. Update, 12(TECHSEAR-6) : 1496-1499; DOI: 10.15740/HAS/AU/12.TECHSEAR(6)2017/1496-1499. 